\title{
Antigenic Relations of Cellulolytic Cocci in the Sheep Rumen
}

\author{
By B. D. W. JARVIS* \\ Department of Biochemistry and Nutrition, University of New England, \\ Armidale, N.S.W., Australia
}

(Accepted for publication 30 December 1966)

SUMMARY

Twenty-five strains of ruminococci were isolated from seven sheep fed chaffed lucerne hay, or mixtures of cereal chaff and lucerne chaff, for 18 months. Antiserum to each strain was produced in rabbits and used to classify the strains by cross-agglutination. Two main groups and a subgroup were identified which served to characterize half (12 of 25$)$ of the strains isolated. Group 1 ( 7 strains) and the subgroup ( 2 strains) were all classified as Ruminococcus albus. Group 2 comprised 3 strains of $R$. flavifaciens. An indirect fluorescent-antibody technique was also used to show antigenic relationships amongst the isolates. Fluorescence cross-reactions were obtained among 13 strains of $R$. albus using group 1 antisera. Similarly a group 2 antiserum labelled 7 of the 12 strains of $R$. flavifaciens isolated. The persistence of these serotypes in the rumen was demonstrated by the isolation of cross-agglutinating strains of $R$. albus from one animal at intervals throughout the experimental period. Recovery of cross-agglutinating strains of $R$. albus and $R$. flavifaciens from more than one animal suggests that a given serotype becomes disseminated among animals which are housed together. Furthermore, the isolation of group 1 and group 2 ruminococci from the same sheep indicates that the group-specific determinants were not dependent on the rumen environment for expression. It is concluded that selection was rigorous enough to maintain recognizably different genetic strains in the rumen against mutation pressure.

\section{INTRODUCTION}

Investigations of the serology of rumen organisms include many studies of streptococci, in sheep and cattle (Perry, Wilson, Newland \& Briggs, 1955; Perry, Newland \& Briggs, 1958; Medrek \& Barnes, 1962 $a, b$ ). Medrek \& Barnes used a ring precipitation test to study the relationships between 149 strains of Streptococcus bovis. They established 12 groups, but these only served to type half the strains. Perry et al. (1958) also observed serological heterogeneity among strains of rumen streptococci. Serological heterogeneity has also been reported among strains of the genus Butyrivibrio (Margherita \& Hungate, 1963; Margherita, Hungate \& Storz, 1964). On the other hand, Briggs (1951) studied the spread of pathogenic strains of Escherichia coli during an epidemic of white scours in calves and showed that serologically identical strains could be recovered from other calves in the same environment. Strains isolated from field cases of the disease were not serologically related. Hobson, Mann \& Oxford (1958) isolated 250 strains of Peptostreptococcus elsdenii. Three agglutination types were distinguished and a few isolated strains belonged to a fourth group. Two of these

* Present address: Department of Bacteriology, University of California, Davis, California 95616. 
serotypes were detected in additional calves and sheep by means of an immunofluorescence technique.

The immunological composition of these bacterial species could be influenced by environmental factors such as the host animal, diet, geographical location and lapse of time. Limitation of these variables may restrict the variety of serotypes so that investigators dealing with animals from one locality encounter only a few serotypes. This paper describes the use of two serological tests, agglutination and immunofluorescence, to characterize strains of sheep rumen cellulolytic cocci, and establish the existence of serological relationships which would permit the detection of ruminococci in situ.

\section{METHODS}

Preparation of suspensions of ruminococci. This investigation was concerned with the relationship between 25 strains of ruminococci whose isolation is described by Jarvis \& Annison (1967).

Antigen suspensions were prepared from cocci grown in $1500 \mathrm{ml}$. clarified rumen liquor broth $(20 \%, \mathrm{v} / \mathrm{v})$ which contained cellobiose $(0.5 \%, \mathrm{w} / \mathrm{v})$. This medium was prepared and maintained under an atmosphere of $100 \% \mathrm{CO}_{2}$. Each fiask was inoculated with a small piece of infected filter paper from a 4-day-old culture on modified Halliwell agar (Jarvis \& Annison, 1967). An increase in turbidity was usually evident after $24 \mathrm{hr}$ at $38 \cdot 5^{\circ}$. Growth was stopped, after 3-4 days, by injecting formalin $(0 \cdot 25 \%$, $\mathrm{v} / \mathrm{v}$ ) and incubating a further $12 \mathrm{hr}$. The cocci were collected by centrifugation of successive portions at $10,800 \mathrm{~g}$ for $20 \mathrm{~min}$., washed three times in formol saline, concentrated to a final volume of about $30 \mathrm{ml}$. and stored at $2^{\circ}$. Antigen concentration was estimated from duplicate Kjedahl nitrogen determinations on each suspension.

Preparation of suspensions for inoculation. Suspensions given without adjuvant were diluted from stock in formol saline and standardized against McFarland's turbidity scale. Freund's incomplete adjuvant (Freund, 1947) was used when an adjuvant-treated antigen was required. The antigen $(50 \mathrm{mg}$. wet-weight) was prepared in formol saline $(3 \mathrm{ml}$.) and homogenized with anhydrous lanolin (1 g.). Liquid paraffin B.P. ( $2 \mathrm{ml}$.) was added and the mixture homogenized again. The adjuvant mixture was transferred to a bijou bottle and stored at $2^{\circ}$. In a few instances the triolein-Tween adjuvant described by Barrie \& Cooper (1964) was used.

Injection schedules. Two rabbits were used for each antigen. One received a saline suspension intravenously, consisting of a total of $5 \mathrm{ml}$. saline suspension (opacity 3 , McFarland's scale) given in seven daily doses increasing from 0.2 to $1.0 \mathrm{ml}$., followed by an interval of 7 days and a second course using a suspension with an opacity of 8 (Hobson, Mann \& Smith, 1962). The second rabbit was given adjuvant-treated antigen in three doses intramuscularly in different sites at 7-day intervals (Kabat \& Mayer, 1961). Each rabbit was bled 7 days after its last injection. A further course of injections was given if the titre at this bleeding was not at least $1 / 640$. Usually the route and vehicle in the second course were not the same as that used in the first. The triolein adjuvant mixture (Barrie \& Cooper, 1964) was used where difficulty had been experienced in getting a response by other methods.

Bleeding for serum. Approximately $5 \mathrm{ml}$. blood were drawn from each rabbit before injections commenced. Normal serum obtained from these bleedings was used as a control to reveal non-specific agglutination. After a course of injections $30-40 \mathrm{ml}$. 
of blood was drawn from the marginal ear vein, allowed to clot and held at $2^{\circ}$ overnight. The immune serum was separated by centrifugation and stored at $-10^{\circ}$.

Determination of antibody concentration in immune serum. The tube agglutination test was used for this purpose. Antigen suspensions were prepared by diluting formolized stock suspensions in saline $(0.85 \%, \mathrm{w} / \mathrm{v}, \mathrm{NaCl}$ in distilled water). These suspensions were made as required and standardized with a Spectronic 20 colorimeter (Bausch \& Lomb Inc., N.Y.) to an extinction of $0.200 \pm 0.005$ at $600 \mathrm{~m} \mu$. Opacity standards were prepared with each antigen suspension used for each series of tests. These standards, representing $0,25,50$ and $75 \%$ agglutination, were prepared by diluting $1.0,0.75,0.50$ and $0.25 \mathrm{ml}$. of standard antigen suspension to $2 \mathrm{ml}$. in saline. The standards were incubated with the test series. Doubling dilutions of antiserum were prepared in unit volumes $(0.5 \mathrm{ml}$.) of saline. Each antigen was also set up with normal serum diluted from $1 / 10$ to $1 / 1280$. After the serum had been diluted, an equal volume $(0.5 \mathrm{ml}$.) of homologous standard antigen was added to each tube and racks of tubes were incubated at $37^{\circ}$ for $2 \mathrm{hr}$ in a water bath and then at $2^{\circ}$ overnight. Tests were read at room temperature. Each tube in a test series was compared with opacity standards prepared using the homologous antigen and scored as: - (negative), $1(25 \%), 2(50 \%), 3(75 \%), 4(100 \%)$. The reciprocal of the highest dilution having a score of 2 was recorded as the titre.

The similarity of different strains was estimated by comparing the titre of each antiserum with homologous and heterologous antigens.

Detection of relationship between strains of ruminococci using an indirect fluorescent antibody technique. Unlabelled rabbit antibody was reacted with antigen and became attached to its surface. This effect was revealed by a second-stage reaction in which the antibody acted as antigen for an anti-rabbit fluorescein-labelled sheep $\gamma$-globulin (Baltimore Biological Laboratory, Inc., Maryland). Indirect labelling was used for comparative purposes because the fluorescein: protein ratio remained constant, although various antigens and antisera were used. Thus the intensity of fluorescence indicated the relative amount of unlabelled rabbit antibody absorbed on the antigen cocci.

Anti-rabbit fluorescein-labelled $\gamma$-globulin was reconstituted in distilled water, and chromatographed on Sephadex G25 (Peters, 1963) to ensure that no free fluorescein was present. An ultraviolet striplamp was used to locate the protein peak and any unbound fluorescein. The protein peak was collected for use as conjugated $\gamma$-globulin. This conjugate $(7.5 \mathrm{ml}$.) was absorbed once with mouse-liver powder $(750 \mathrm{mg}$.). This mixture was shaken for $1 \mathrm{hr}$ at room temperature and then centrifuged $(22,000 \mathrm{~g}$ for $30 \mathrm{~min}$.). The supernatant-absorbed conjugate solution was recovered, preserved with Thiomersal (B.D.H., England), and stored at $-10^{\circ}$ until required.

Slides of each antigen were prepared from suitable dilutions of the concentrated formolized suspensions in phosphate-buffered normal saline. One drop of each diluted suspension was spread on an ultraviolet-transmitting slide (Shandon Scientific Co., Cromwell Place, London S.W. 7) and allowed to dry in air. Subsequent treatment of the slides followed Cherry, Goldman \& Carski (1960) and Hobson et al. (1962). Smears were fixed by immersion in redistilled acetone for $20 \mathrm{~min}$., removed, allowed to dry in air, then moistened with buffered saline. A large Petri dish containing wet filter paper and several glass rods was used as a moist incubation chamber. Slides were arranged, smear uppermost, on the glass rods. One drop of undiluted rabbit 


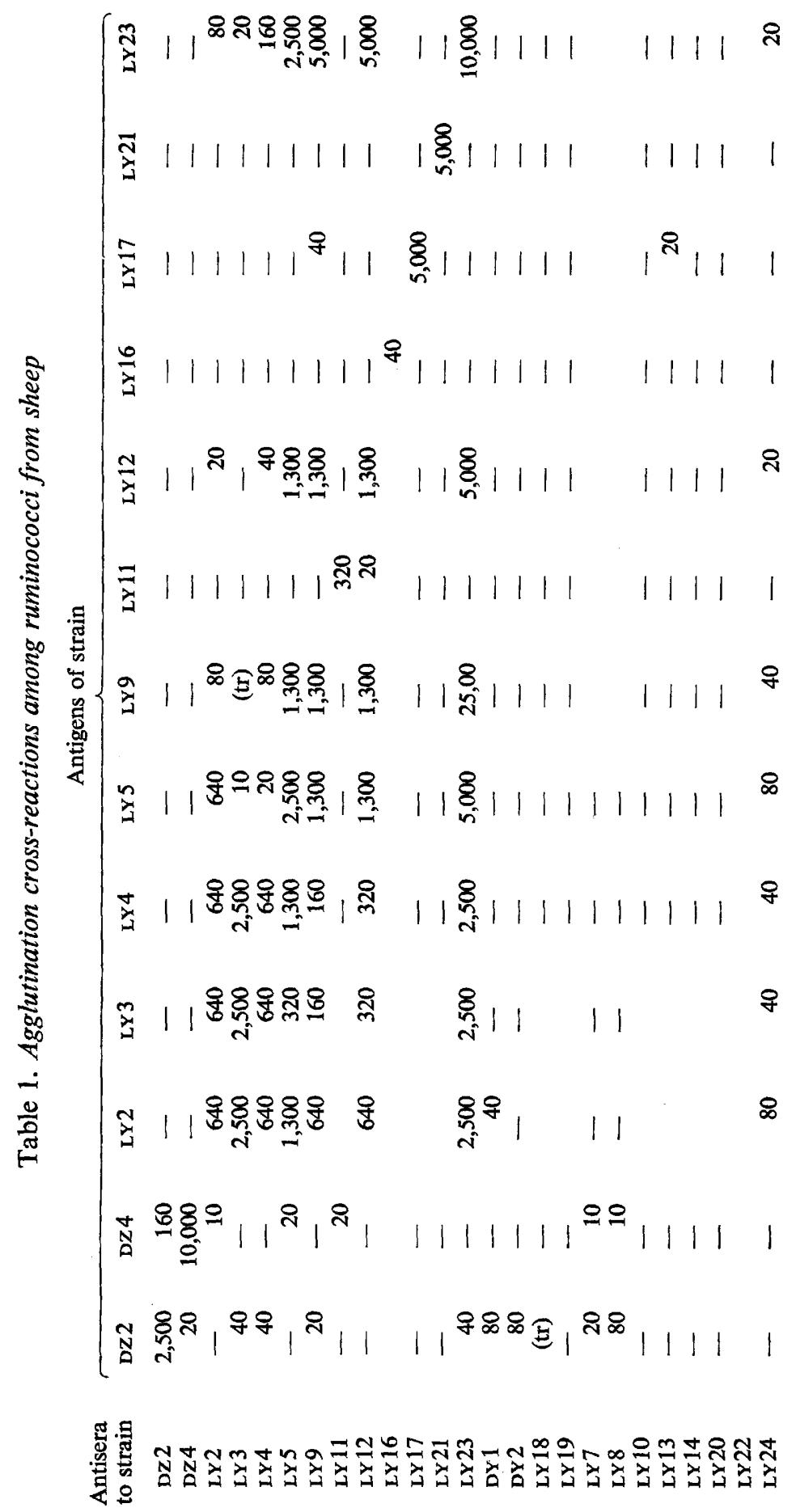




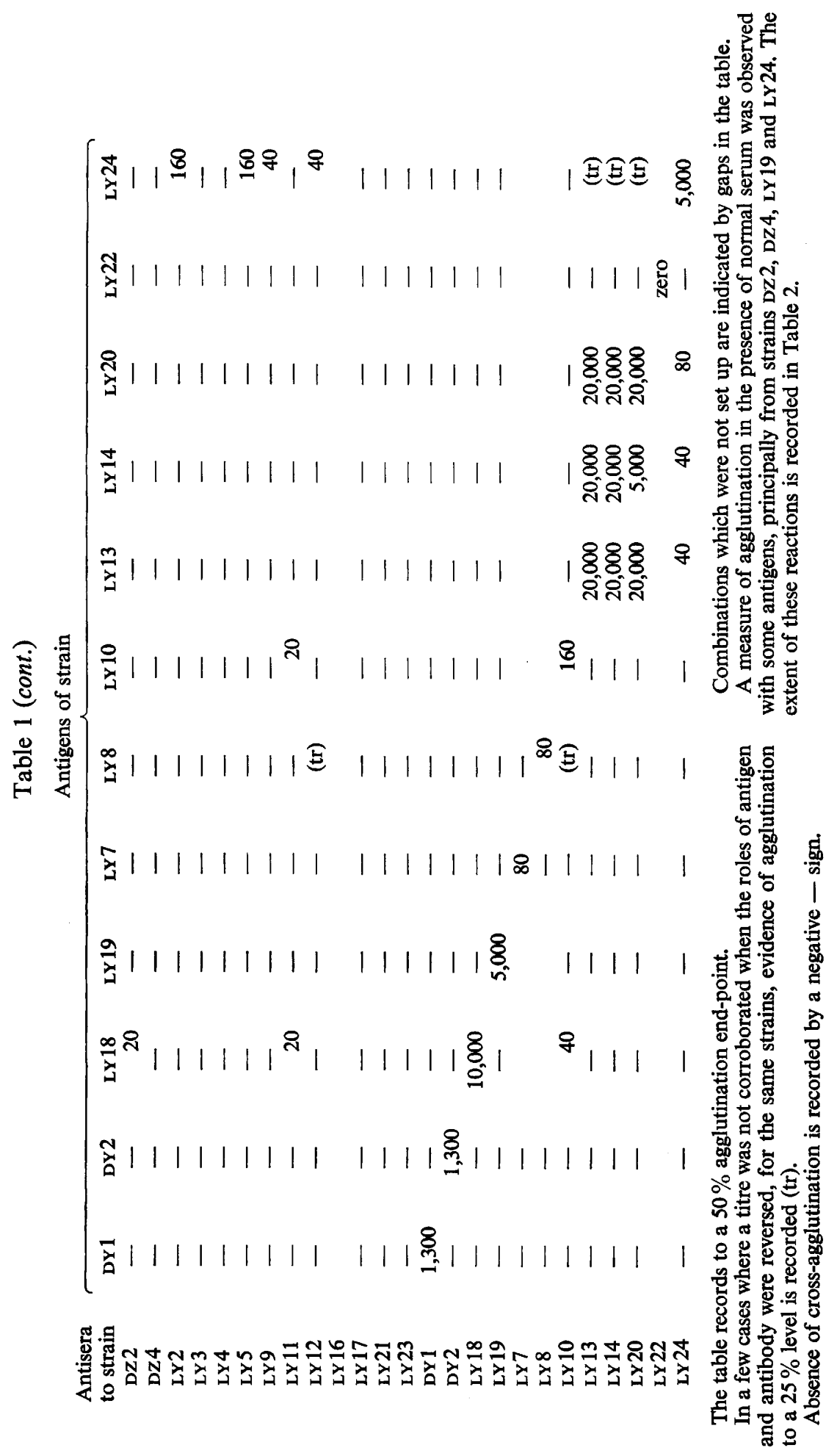


antiserum was added to each slide and the whole batch incubated for $30 \mathrm{~min}$. at $37^{\circ}$. The protein not absorbed at the surface of the cocci was completely rinsed from each slide by three successive $5 \mathrm{~min}$. washes in fresh buffered saline. Slides were individually rinsed with buffered saline between each wash. The slides were then rearranged in the moist chamber and a drop of undiluted absorbed fluoresceinconjugated $\gamma$-globulin applied to each. After incubation for a further $30 \mathrm{~min}$. at $37^{\circ}$ the slides were rinsed with the same care as before, a drop of mountant (Univert aqueous mountant; G. T. Gurr Ltd., London) was added and a coverslip applied to each slide whilst still moist. Slides were examined within $2 \mathrm{hr}$ of preparation. Positive and negative controls were set up with each batch of slides. These comprised homologous antigen against rabbit antiserum and antigen against normal rabbit serum.

The preparations were examined by using a standard G.F.L. microscope and multi-purpose microscope illuminator (Carl Zeiss). The lamp and microscope were mounted on a hardboard base. The illuminator was fitted with a high-pressure mercury lamp, H.B.O. $200 \mathrm{~W}$. (Osram) and connected to the main power supply through a choke 392622 (Carl Zeiss). Exciter filters comprised KG. 1 heat protection filter (permanently in the light path), BG 12, BG 3, and UG 5, UG 1. BG filters were used for blue-light fluorescence, whilst the U.G. series were used when ultraviolet excitation was required. On the microscope, the diaphragm insert of the standard built-in illuminator was replaced by a mirror and an optical system comprising a 1.3 NA bright-field condenser; $\times 10, \times 40, \times 100$ achromatic objectives and $\mathrm{P} \times 10$ eyepiece were used. The binocular head was replaced by a straight monocular tube. A barrier filter intermediate tube was located between the objective nose-piece and monocular tube. It contained two neutral filters ( $\mathrm{N} 0 \cdot 1$ and $\mathrm{N} 0 \cdot 01$ ) and six barrier filters (designated $41,44,47,50,53,-65$ ). Estimates of fluorescent intensity were made with $\times 40$ objective and blue-light fluorescence obtained with BG 12 and BG 3 exciter filters coupled with 53 and 44 barrier filters. When several slides were to be examined, the fluorescent image of the positive control was sharply focused so that other slides could then be slipped in with only minor focusing adjustment, thus facilitating comparisons. When no fluorescent image was visible the presence of cocci in the field was verified by bright-field observation. Estimates of fluorescent intensity were recorded according to the following scale after Cherry et al. (1960):4+, maximal fluorescence, brilliant yellow-green; $3+$, bright yellow-green fluorescence; $2+$, less brilliant but definitely fluorescent, $1+$; fluorescent but dull; tr., a faint fluorescent glow.

\section{RESULTS}

Twenty-five strains of rumen cellulolytic cocci were used to immunize rabbits and produce specific antisera of high titre. A majority of strains (18 of 25) provoked titres of 1/1200 or more after one course of injections. This result was obtained in a second group ( 2 of 25) after a second course of injections. But a third group (5 of 25) appeared to be incapable of eliciting a satisfactory agglutinin response. Antigen was the major factor determining the titre of immune serum. In 21 of 25 strains the mode of immunization had no significant effect on the agglutinin titre of the antiserum collected from two differently treated rabbits. To some extent these differences in antigenicity could be related to species differences. Among Ruminococcus albus and $R$. flavifaciens 10 of 13 and 8 of 12 , respectively, were good antigens, but whereas a 
Table 2. Extent of agglutination of sheep ruminococci by normal rabbit serum

\begin{tabular}{cccc} 
Strain as antigen & \multicolumn{2}{c}{ Agglutination titre at three end-points } \\
& $\begin{array}{c}25 \% \\
\text { agglutinated }\end{array}$ & $\begin{array}{c}50 \% \\
\text { agglutinated }\end{array}$ & $\begin{array}{c}75 \% \\
\text { agglutinated }\end{array}$ \\
LY14 & 10 & - & - \\
LY18 & 20 & - & - \\
LY20 & 20 & - & - \\
LY22 & 20 & - & - \\
LY13 & 40 & 10 & - \\
DZ4 & 20 & 10 & - \\
LY24 & 160 & 40 & - \\
LY19 & 160 & 160 & - \\
DZ2* & - & 160 & - \\
DZ2 & - & 160 & - \\
DZ2 & 320 & 320 & - \\
DZ2 & - & - & - \\
DZ2 & - & & -
\end{tabular}

* Strain Dz2 was compared against several samples of normal serum from different rabbits.

Table 3. A comparison of cross-reactions detected by indirect immunofluorescence (F.A.) with those detected by agglutination $(\mathrm{Ag})$, for three antisera and strains of sheep ruminococci

\begin{tabular}{|c|c|c|c|c|c|c|}
\hline \multirow{2}{*}{$\begin{array}{c}\text { Strain as } \\
\text { antigen*, } \dagger\end{array}$} & \multicolumn{2}{|c|}{ LY9 antisera } & \multicolumn{2}{|c|}{ LY23 antisera } & \multicolumn{2}{|c|}{ LY14 antisera } \\
\hline & Ag titre & F.A. $\ddagger$ & Ag titre & F.A. $\ddagger$ & Ag titre & F.A.: \\
\hline $\mathrm{Dz} 2$ & 20 & $3+$ & 40 & $1+$ & - & $2+$ \\
\hline DZ4 & - & $2+$ & - & $1+$ & - & $1+$ \\
\hline LY 2 & 640 & $3+$ & 2,500 & $2+$ & & - \\
\hline LY3 & 160 & $4+$ & 2,500 & $3+$ & & - \\
\hline LY 4 & 160 & $2+$ & 2,500 & & - & - \\
\hline LY5 & 1,300 & $3+$ & 5,000 & $3+$ & - & - \\
\hline LY9 & 1,300 & $4+$ & 2,500 & $3+$ & - & - \\
\hline LY 11 & - & $3+$ & - & $3+$ & - & - \\
\hline LY 12 & 1,300 & $4+$ & 5,000 & $2+$ & - & $1+$ \\
\hline LY 16 & - & $2+$ & - & $4+$ & - & $\operatorname{tr}$ \\
\hline LY17 & 40 & $2+$ & - & $4+$ & 一 & tr \\
\hline LY21 & - & $2+$ & - & $2+$ & - & tr \\
\hline LY 23 & 5,000 & $2+$ & 10,000 & $4+$ & - & $4+$ \\
\hline DY 1 & - & - & - & - & - & - \\
\hline DY 2 & - & - & - & - & - & $4+$ \\
\hline LY18 & - & - & - & - & - & - \\
\hline LY19 & - & - & - & - & - & - \\
\hline LY7 & - & - & - & - & - & $4+$ \\
\hline LY 8 & - & - & - & - & - & - \\
\hline LY 10 & - & - & - & - & - & $2+$ \\
\hline LY13 & - & - & - & - & 20,000 & $4+$ \\
\hline LY14 & - & - & - & - & 20,000 & $4+$ \\
\hline LY20 & - & - & - & - & 20,000 & $4+$ \\
\hline LY 22 & - & - & - & $\mathrm{tr}$ & - & - \\
\hline LY 24 & 40 & - & - & - & (tr) & $4+$ \\
\hline
\end{tabular}

* Antigens DZ2 to LY 23 were diplococci; DY1 to LY 19 were short-chain streptococci, whilst LY 7 to LY 24 were long-chain streptococci.

$\dagger$ Group I comprised LY2, LY3, LY4, LY 5, LY9, LY12, and LY23. Group II comprised LY 13, LY14 and $L Y 20$.

$\ddagger$ The method of scoring fluorescence is described in the text. 
further 2 of $13 R$. albus strains gave titres of $1 / 1200$ or more when the course of injections was repeated, and only one was classed as a poor antigen, 4 of 12 of $R$. flavifaciens strains did not provoke an adequate antibody response after repeated injection.

Agglutination cross-reactions are recorded in Table 1. Titres of $1 / 80$ and above are considered to represent effects which could not be confused with non-specific agglutination. In the case of strain Dz2 the titres obtained with immune serum frequently did not exceed those with normal serum (Table 2) and their significance is doubtful. On the other hand, those antigens not listed in Table 2 did not agglutinate with normal serum and cross-reactions in which they were involved may be significant below $1 / 80$. Table 1 indicates that half the strains $(13$ of 25$)$ showed some relationship with other strains. A further group (5 of 25 ) were poor antigens, a feature which would tend to prevent the establishment of an agglutination cross-reaction. The remainder (7 of 25) were serologically distinct and showed no cross-reactivity. Table 1 is arranged so that similar morphological types are brought together. Two well-defined groups are evident. Group 1 consisted of strains LY 2, LY 3, LY 4, LY 5, LY 9, LY 12, LY 23 (all diplococci). Group 2 comprised strains LY13, LY 14, LY 20 (all streptococci). The DZ series formed a third minor group unrelated to groups 1 and 2. Strain LY 24 was of interest because, although a large part of its antigenic character was probably unique, it had features in common with both group 1 and group 2 strains and represented an intermediate type.

\section{Table 4. Validity of the indirect fluorescent-antibody technique used to label antigens of sheep ruminococci}

Components of the labelling reaction

\begin{tabular}{|c|c|c|c|c|}
\hline $\begin{array}{l}\text { Strain as } \\
\text { antigen }\end{array}$ & & Rabbit serum & $\begin{array}{l}\text { Fluorescein- } \\
\text { labelled } \\
\text { anti-rabbit } \\
\gamma \text {-globulin }\end{array}$ & Result \\
\hline LY 23 & + & None & +label & No fluorescence \\
\hline LY 23 & + & $1 / 10$ normal serum & +label & $\begin{array}{l}\text { Very faint glow, no detectable } \\
\text { organisms by blue-light } \\
\text { fluorescence }\end{array}$ \\
\hline LY 23 & + & $\begin{array}{l}\text { 1/10 absorbed specific } \\
\text { antiserum* }\end{array}$ & +label & No fluorescence \\
\hline LY 23 & + & 1/10 specific antiserum & +label & $\begin{array}{l}\text { Bright spherical cocci on } \\
\text { a black background }\end{array}$ \\
\hline
\end{tabular}

* Concentrated homologous antigen suspension $(1 \mathrm{ml}$.) shaken with undiluted antiserum $(1 \mathrm{ml}$.) at room temperature for $1 \mathrm{hr}$. Then centrifuged for $20 \mathrm{~min}$. at $22,000 \mathrm{~g}$ and $2^{\circ}$. The supernatant fluid was used in this test.

Results obtained when the indirect fluorescent-antibody technique was used to detect cross-reactions among ruminococci are recorded in Table 3. It is evident that antisera to group 1 strains reacted with a wider range of antigens than was revealed by agglutination. In spite of this they exhibited a remarkable specificity for diplococci. Group 2 was represented by LY 14 antiserum. In this case the strains showing crossfluorescence did not correspond so well with the morphological type. Some strepto- 
coccal strains (5 of 12) did not fluorescence with LY 14 antiserum, whilst some diplococcal strains ( 4 of 13) were labelled by LY 14 antiserum.

Table 4 demonstrates that the fluorescent labelling observed was dependent on the presence of specific antibody.

\section{DISCUSSION}

The conclusion that most taxonomic groups of rumen bacteria include a variety of serotypes (Bryant, 1963) can be extended to ruminococci. Three groups were identified by cross-agglutination and these served to classify 13 of 25 strains. The agglutination data do not suggest that the members of this genus are any more closely related than are members of the genus Butyrivibrio (Margherita \& Hungate, 1963) or Peptostreptococcus elsdenii (Hobson et al. 1958), but a broader relationship was observed by using immunofluorescence. Agglutination is concerned with surface antigens, but the existence of antigenic determinants which normally take no part in agglutination can be detected by using cell-wall fractions in place of intact organisms (Cummins, 1954). Such fractions cross-agglutinate more extensively than intact organisms, because determinants associated with the inner structure of the cell wall are exposed when the walls are broken. Some of these antigenic groups can also be demonstrated by means of fluorescent antibodies. Moody, Ellis \& Updyke (1958) used the fluorescent-antibody technique to detect group A streptococci. They found marked cross-reactions between members of Lancefield's groups A and C, and overcame this by absorbing group $\mathrm{A}$ antisera with group $\mathrm{C}$ organisms. In this case the group-specific determinants are terminal groups on rhamnose side-chains attached to the bacterial surface. Cross-reactivity is associated with rhamnose-rhamnose linkages, common to the side-chains of both groups. These are normally masked by the terminal groups (McCarty, 1956; Karakawa, Krause \& Borman, 1965). The cross-fluorescence observed among ruminococci may be due to common structural features such as those described for streptococci.

Two species of ruminococci have been described, Ruminococcus albus (Hungate, 1957) and R. flavifaciens (Sijpesteijn, 1948). These are distinguished on the basis of morphology and fermentation products. The physiological characteristics of the strains considered here were used to construct a dendrogram which had two main branches corresponding with the accepted species (Jarvis \& Annison, 1967). Comparison of the relationships established by serological methods with those based on physiological data shows that strains which cross-agglutinated are clustered in the same branches of the dendrogram. Thus group 1 strains are all classified as $R$. albus and the three group 2 strains are classified as $R$. flavifaciens. The DZ strains did not cross-agglutinate with group 1 strains, although classified as $R$. albus. Cross-fluorescence data generally revealed additional serological relationships with members of the same physiological group. Thus group 1 antisera reacted with all the strains classified as $R$. albus but not with strains classified as $R$. flavifaciens. There are two anomalies. Strains LY16 and LY17, which occupied an intermediate position on physiological grounds, fluoresced brilliantly when labelled with group 1 antisera, indicating that they were related to group 1 strains. Conversely, strains DZ2 and $\mathrm{DZ} 4$, each of which was related to an authentic $R$. albus strain on physiological grounds, reacted as intermediates and cross-fluoresced with antisera from group 1 (R. albus) and group 2 ( $R$. flavifaciens). The lack of serological relationship between 
$R$. albus and $R$. flavifaciens provides independent evidence for the existence of two species of rumen cellulolytic cocci and corroborates the existing monothetic classification.

A study of these serological data in relation to the origin of each strain (Jarvis \& Annison, 1967) indicates that organisms showing group 1 antigenic character were repeatedly isolated from sheep C6 over a period of 18 months. This supports the conclusion that an established rumen population is relatively stable although it is in a state of dynamic equilibrium (Kay \& Hobson, 1963). Strains LY2, LY 3 and LY 4 were isolated from sheep C 6 several months before strains LY 5 and LY 23. Agglutination cross-reactions between strains LY 2, LY 3 and LY 4 indicate a close relationship. But the titres of antisera to strains LY2, LY 3 and LY 4 with their homologous antigens were noticeably higher than those with either LY 5 or LY 23 antigen, suggesting that their relationship with the later isolates was less marked. In the reverse situation LY 5 and LY 23 antisera reacted strongly with LY 2, LY 3 and LY 4 antigens. These results indicate that group 1 ruminococci were relatively stable during this experiment and provide only slight evidence of the progressive changes in intestinal flora postulated by Emslie-Smith (1961) and Medrek \& Barnes (1962b).

The detection of group 1 ruminococci in sheep C76 as well as sheep C6 suggests that an interchange of ruminococcal strains between animals occurs. Such a transmission of microbial species between animals has been reported by other workers (Briggs, 1951; Eadie, 1962).

The isolation of strains LY 9 (group 1) and LY 13 (group 2) from sheep C76 indicates that group-specific determinants were not dependent on the rumen environment, and it can be inferred that the genetic capacity to produce group 1 antigenic determinants persisted in the intestinal flora of sheep C6 over a period of 18 months. This may have been due, as Cummins (1962) suggested, to the relative stability of cell-wall structures compared with those parts of the organism which must adapt to changing external conditions, but it is possible that selection was rigorous enough to maintain a recognizable genetic strain against mutation pressure.

The author wishes to thank Mr M. M. MacKinnon, Senior Lecturer in Preventive Medicine at the University of New England, for helpful discussion during the course of this work.

\section{REFERENCES}

BARrie, J. U. \& CoOper, G. N. (1964). Enhancement of the primary antibody response to particulate antigens by simple lipids. J. Immunol. $92,529$.

Briggs, C. (1951). The nutritive value of colostrum for the calf. 6. The ' $K$ ' antigens of Bacterium coli. Br. J. Nutr. 5, 349.

BRYANT, M. P. (1963). Symposium on microbial digestion in ruminants: identification of groups of anaerobic bacteria active in the rumen. J. anim. Sci. $22,801$.

Cherry, W. B., Goldman, M. \& Carski, T. R. (1960). Fluorescent antibody techniques in the diagnosis of communicable diseases. Public Health Service Publication, no. 729. U.S. Government Printing Office, Washington.

Cummins, C. S. (1954). Some observations on the nature of the antigens in the cell wall of Corynebacterium diphtheriae. Br. J. exp. Path. 35, 166.

Cummins, C. S. (1962). Immunochemical specificity and the location of antigens in the bacterial cell. Symp. Soc. gen. Microbiol. 12, 212.

EADIE, J. M. (1962). The development of rumen microbial populations in lambs and calves under various conditions of management. J. gen. Microbiol. 29, 563. 
EMSLIE-SMith, A. H. (1961). Observations on the secular succession of types of $E$. coli and related organisms in the faecal flora of an adult human subject. J. appl. Bact. 24, viii.

FreUND, J. (1947). Some aspects of active immunization. A. Rev. Microbiol. 1, 291.

Hobson, P. N., MANn, S. O. \& OXford, A. E. (1958). Some studies on the occurrence and properties of a large Gram-negative coccus from the rumen. J. gen. Microbiol. 19, 462.

Hobson, P. N., ManN, S. O. \& SMith, W. (1962). Serological tests of a relationship between rumen selenomonads in vitro and in vivo. J. gen. Microbiol. 29, 265.

Hungate, R.E. (1957). Microorganisms in the rumen of cattle fed a constant ration. Can.J. Microbiol. $3,289$.

JARVIS, B. D. W. \& ANNISON, E. F. (1967). Isolation, classification and nutritional requirements of cellulolytic cocci in the sheep rumen. J. gen. Microbiol. 47, 295.

KABAT, E. A. \& MAYER, M. M. (1961). Experimental Immunochemistry, 2nd ed. Springfield, Illinois, U.S.A.: C. C. Thomas.

Karakawa, W. W., Krause, R. M. \& Borman, E. K. (1965). Immunochemical aspects of the crossreactivity between groups $\mathrm{A}$ and $\mathrm{C}$ streptococci as detected by the fluorescent antibody technique. J. Immunol. 94, 282.

Kay, R. N. B. \& Hobson, P. N. (1963). Reviews of the progress of dairy science. Sect. A, pts. 1 and 2. J. Dairy Res. 30, 261.

Margherita, S. S. \& Hungate, R. E. (1963). Serological analysis of Butyrivibrio from the bovine rumen. J. Bact. 86, 855 .

Margherita, S. S., Hungate, R. E. \& Storz, H. (1964). Variation in rumen Butyrivibrio strains. J. Bact. 87, 1304.

MCCARTY, M.(1956). Variation in the group-specific carbohydrate of group A streptococci. II. Studies on the chemical basis for serological specificity of the carbohydrates. J. exp. Med. 104, 629.

MedreK, T. F. \& Barnes, E. M. (1962a). The distribution of group D streptococci in cattle and sheep. J. appl. Bact. 25, 159.

MEDREK, T. F. \& BARNES, E. M. (1962b). The physiological and serological properties of Streptococcus bovis and related organisms isolated from cattle and sheep. J. appl. Bact. 25, 169.

Moody, M. D., Ellis, E. C. \& UpDYKe, E. (1958). Staining bacterial smears with fluorescent antibody. IV. Grouping streptocci with fluorescent antibody. J. Bact. 75, 553.

Perry, K. D., Newland, L. G. M. \& Briggs, C. A. E. (1958). Group-D rumen streptococci with type antigens of group N. J. Path. Bact. 76, 589.

Perry, K. D., Wilson, M. K., Newland, L. G. M. \& Briggs, C. A. E. (1955). The normal flora of the bovine rumen. III. Quantitative and qualitative studies of rumen streptococci. J. appl. Bact. 18, 436.

Peters, H. (1963). Construction and use of a small Sephadex column for the separation of fluorescent antibodies. Stain Technol. 38, 260.

SupesteIJn, A. K. (1948). Cellulose-decomposing bacteria from the rumen of cattle. Ph.D. thesis, University of Leiden. 